\title{
PENGETAHUAN TERHADAP KEPATUHAN MENGKONSUMSI TABLET FE PADA IBU HAMIL TRIMESTER III
}

\author{
Rochany Septiyaningsih $^{1}$, Frisca Dewi Yunadi², Septiana Indratmoko ${ }^{3}$ \\ ${ }^{1,2,3)}$ STIKES Al Irsyad Al Islamiyyah Cilacap \\ rochany.septiyaningsih87@gmail.com
}

\begin{abstract}
ABSTRAK
Anemia dalam kehamilan dapat mempengaruhi nilai kesejahteraan sosial ekonomi masyarakat dan kualitas sumber daya manusia, serta berpotensi membahayakan ibu dan anak. Oleh karena itu, anemia dalam kehamilan perlu mendapatkan perhatian yang serius dari semua pihak yang terkait dalam memberikan pelayanan kesehatan. World Health Organization menyatakan prevalensi anemia dalam kehamilan di seluruh dunia adalah $41,8 \%$ pada tahun 2010. Prevalensi anemia dalam kehamilan di Indonesia mengalami peningkatan yaitu pada tahun 2013 sebesar $37,1 \%$ dan meningkat pada tahun 2018 sebesar $48,9 \%$. Upaya Pemerintah yang sudah dilakukan adalah dengan program pemberian suplementasi tablet besi pada ibu hamil. Pengetahuan yang dimiliki ibu hamil tentang anemia sangat penting, karena akan mempengaruhi perilaku kesehatan yang dilakukan sehingga dapat menurunkan risiko anemia selama kehamilan. Penelitian ini penelitian kuantitatif dengan pendekatan cross-sectional. Sampel menggunakan sampel minimal yaitu $30 \mathrm{ibu}$ hamil trimester III, dengan teknik accidental sampling. Analisis dalam penelitian ini adalah Chi-Square. Hasil uji Chi-Square menunjukkan bahwa ada hubungan tingkat pengetahuan dengan kepatuhan mengkonsumsi tablet Fe pada ibu hamil trimester III di Puskesmas Cilacap Selatan I ( $p$-value $=0,000)$. Ada hubungan pengetahuan dengan kepatuhan mengkonsumsi tablet Fe pada ibu hamil trimester III di Puskesmas Cilacap Selatan I.
\end{abstract}

Kata kunci : ibu hamil, kepatuhan, pengetahuan, tablet Fe

\section{Abstract}

Anemia in pregnant women will affect the value of socio-economic well-being and the quality of human resources and potentially harm both mother and child. Hence, it needs serious attention in providing health services in the future from all the parties involved. The World Health Organization stated that the prevalence of anemia in pregnancy worldwide was $41.8 \%$ in 2010. The prevalence of anemia in pregnancy in Indonesia increased in 2013 by 37.1\% and in 2018 by 48.9\%. The efforts by providing iron tablet supplementation programs for pregnant women. Knowledge about anemia is essential to reduce the risk of anemia during pregnancy. This research was a quantitative study with a cross-sectional approach. The sample used a minimum sample of 30 pregnant women in their trimester III stages, with an accidental sampling technique. The analysis used in this study was Chi-Square. The Chi-Square test shows a relationship between the level of knowledge and compliance with consuming Fe tablets ( $p$-value $=0.000)$ and a relationship between the knowledge and compliance with consuming Fe tablets in thirdtrimester pregnant women at the Cilacap Selatan I Health Center.

Keywords: pregnant women, compliance, knowledge, Fe tablets 


\section{PENDAHULUAN}

Salah satu masalah nasional yang dialami oleh ibu hamil adalah anemia. Anemia dalam kehamilan dapat mempengaruhi nilai kesejahteraan nasional masyarakat dan kualitas sumber daya manusia, serta berpotensi membahayakan ibu dan anak. Oleh karena itu, anemia dalam kehamilan perlu mendapatkan penanganan yang serius dari semua pihak sebagai pemberi layanan kesehatan pada masa yang akan datang (Manuaba, 2010). Salah satu tujuan yang tertuang dalam Suistainable Development Goals (SDG's) yaitu menghilangkan kelaparan serta mencapai ketahanan pangan dan gizi yang baik. Anemia menjadi salah satu masalah malnutrisi serius di dunia yang harus ditangani dengan tepat (UNICEF, 2017).

Anemia dalam kehamilan merupakan kondisi dimana ibu hamil mengalami kekurangan kadar hemoglobin. Pada ibu hamil trimester satu dan tiga yang memiliki kadar hemoglobin dalam darah kurang dari $11 \mathrm{gr} / \mathrm{dl}$ dikatakan anemia, sedangkan pada ibu hamil trimester dua dikatakan anemia apabila kadar hemoglobin dalam darah kurang dari 10,5 gr/dl (Kemenkes RI, 2014).

\section{Data dari World Health Organization} (WHO) 2010 menunjukkan angka kejadian anemia dalam kehamilan di dunia adalah $41,8 \%$. Angka kejadian anemia dalam kehamilan di Indonesia mengalami peningkatan yaitu pada tahun 2013 sebesar 37,1\% dan meningkat pada tahun 2018 sebesar 48,9\% (Riskesdas, 2018).

Upaya penurunan angka kejadian anemia yang sudah dilakukan oleh pemerintah adalah dengan program pemberian suplementasi tablet besi pada ibu hamil (Parulian et al., 2016). Berdasarkan peraturan pemerintah Permenkes No. 88 tahun 2014 tentang standar pemberian tablet tambah darah selama hamil dan pada wanita usia subur menyatakan bahwa wanita usia subur dan ibu hamil dianjurkan untuk mengkonsumsi tablet tambah darah guna mencegah terjadinya anemia. Tablet tambah darah yang dianjurkan untuk ibu hamil adalah minimal mengkonsumsi 90 butir selama kehamilannya untuk menurunkan risiko terjadinya anemia dan menjaga agar janin dapat tumbuh dengan baik (Kehutanan et al., 2008). Berdasarkan (Riskesdas, 2018) ibu hamil yang sudah mengkonsumsi tablet tambah darah sudah mencapai lebih dari 90 butir selama kehamilan sebesar $61,9 \%$ dan yang kurang dari 90 butir selama kehamilan sebesar 38,1\%.

Anemia dalam kehamilan dapat mengakibatkan beberapa komplikasi baik bagi ibu maupun janinnya. Dampak yang dapat terjadi karena anemia dalam kehamilan adalah abortus, persalinan prematur, gangguan pertumbuhan dan perkembangan janin, rentan terjadi infeksi, perdarahan antepartum, ketuban pecah dini (KPD), gangguan kontraksi intrapartum, kala I lama, partus lama, perdarahan postpartum, serta gangguan pengeluaran Air Susu Ibu (ASI) (Setiawati et al., 2014).

Perilaku kesehatan dapat terbentuk dengan baik, salah satunya dipengaruhi oleh pengetahuan (Notoatmodjo, 2007). Pengetahuan yang dimiliki ibu hamil mengenai akibat dan pencegahan anemia sangat penting, karena akan mempengaruhi perilaku kesehatan yang dilakukan sehingga dapat menurunkan risiko terjadinya anemia selama kehamilan (Mandagi, 2019)eklampsi, infection diseases, and placenta previa, which all of it have a source from iron deficiency anemia. The cohort register of pregnant mother at Public Health Service Moyudan state that the pregnant mother number 2007 is 377 person and 180 (47,75\%. Pengetahuan ibu hamil tentang anemia juga memiliki hubungan dengan terjadinya anemia selama kehamilan (Ayu Wulandari, 2018)

Pengetahuan yang dimiliki oleh ibu hamil dapat menjadi faktor yang berhubungan dengan perilaku ibu hamil dalam mengkonsumsi tablet Fe (Mardhiah \& Marlina, 2019). Penelitian 
lain menunjukkan bahwa ada hubungan yang signifikan antara tingkat pengetahuan ibu hamil tentang anemia dengan kepatuhan mengkonsumsi tablet Fe (Sulistiyanti, 2015). Ketidakpatuhan mengkonsumsi tablet Fe selama kehamilan juga dapat mengakibatkan kejadian anemia (Studi et al., 2016).

Puskesmas Cilacap Selatan I merupakan salah satu puskesmas di Kabupaten Cilacap yang memberikan pelayanan kesehatan ibu dan anak. Pada tahun 2018 di wilayah kerja Puskesmas Cilacap Selatan I terdapat 788 ibu hamil yang memeriksakan kehamilannya, setelah dilakukan pemeriksaan hemoglobin $(\mathrm{Hb}) 93$ ibu hamil mengalami anemia. Data dari Dinas Kesehatan Kabupaten Cilacap jumlah ibu hamil di Kabupaten Cilacap Tahun 2018 sebanyak 30.905 orang. Bila dibandingkan jumlah ibu hamil di Puskesmas Cilacap Utara, Cilacap Tengah dan Cilacap Selatan didapatkan data jumlah ibu hamil dengan anemia di Puskesmas Cilacap Selatan I menempati urutan tertinggi sebanyak 788 ibu hamil dan sebanyak $93(11,8 \%)$ ibu hamil mengalami anemia.

Tujuan penelitian ini adalah untuk mengetahui adanya hubungan antara pengetahuan terhadap kepatuhan mengkonsumsi tablet $\mathrm{Fe}$ pada ibu hamil trimester III di Puskesmas Cilacap Selatan I.

\section{METODOLOGI}

Jenis penelitian ini termasuk penelitian kuantitatif dengan pendekatan cross-sectional, karena variabel yang diteliti pada penelitian ini diperoleh pada waktu yang bersamaan. Penelitian ini dilakukan di wilayah kerja Puskesmas Cilacap Selatan I. Sampel yang digunakan dalam penelitian ini menggunakan sampel minimal yaitu $30 \mathrm{ibu}$ hamil trimester III. Teknik pengambilan sampel pada penelitian ini adalah accidental sampling. Waktu pengambilan data dari bulan Juli-September 2020. Pengumpulan data dimulai dari pengisian formulir kesediaan menjadi responden kemudian dilanjutkan dengan pengisian kuesioner pengetahuan dan kepatuhan mengkonsumsi tablet Fe. Analisis univariat dalam penelitian ini menggambarkan distribusi frekuensi pengetahuan dan kepatuhan mengkonsumsi tablet Fe. Penelitian ini di analisis dengan menggunakan Chi-Square.

\section{HASIL}

Hasil penelitian ini dideskripsikan dalam bentuk tabel yang terdiri dari tabel distribusi frekuensi pengetahuan, kepatuhanmengkonsumsi tablet $\mathrm{Fe}$ dan hubungan antara pengetahuan dengan kepatuhan mengkonsumsi tablet Fe pada ibu hamil trimester III di Puskesmas Cilacap Selatan I.

Tabel 1. Distribusi Frekuensi Pengetahuan Ibu Hamil Trimester III di Puskesmas Cilacap Selatan I

\begin{tabular}{lcc}
\hline \multicolumn{1}{c}{ Variabel } & f & \% \\
\hline Pengetahuan & & \\
Baik & 16 & 53,3 \\
Cukup & 12 & 40,0 \\
Kurang & 2 & 6,7 \\
\hline Jumlah & $\mathbf{3 0}$ & $\mathbf{1 0 0}$ \\
\hline
\end{tabular}

Sumber: Data Primer, 2020

Pada tabel 1 menunjukkan bahwa sebagian besar ibu hamil trimeseter III memiliki pengetahuan baik sebanyak $16 \mathrm{ibu}$ hamil $(53,3 \%)$, sebagian kecil memiliki pengetahuan kurang sebanyak 2 ibu hamil $(6,7 \%)$ dan memiliki pengetahuan cukup sebanyak $12 \mathrm{ibu}$ hamil (40,0\%).

Tabel 2. Distribusi Frekuensi Kepatuhan

Mengkonsumsi Tablet Fe pada Ibu Hamil Trimester III di Puskesmas Cilacap Selatan I

\begin{tabular}{ccc}
\hline Variabel & f & $\%$ \\
\hline Kepatuhan & & \\
\hline
\end{tabular}




\begin{tabular}{lcc}
\hline \multicolumn{1}{c}{ Variabel } & f & \% \\
\hline Patuh & 20 & 66,7 \\
Tidak Patuh & 10 & 33,3 \\
\hline Jumlah & $\mathbf{3 0}$ & $\mathbf{1 0 0}$ \\
\hline
\end{tabular}

Sumber: Data Primer, 2020
Pada tabel 2 menunjukkan bahwa ibu hamil trimester III yang patuh mengkonsumsi tablet Fe sebanyak 20 ibu hamil (66,7\%) dan yang tidak patuh mengkonsumsi tablet Fe sebanyak 10 ibu hamil $(33,3 \%)$.

Tabel 3. Hubungan Pengetahuan Terhadap Kepatuhan Dalam Mengkonsumsi Tablet Fe pada Ibu Hamil Trimester III di Puskesmas Cilacap Selatan I

\begin{tabular}{|c|c|c|c|c|c|c|c|}
\hline \multirow{3}{*}{ Pengetahuan } & \multicolumn{6}{|c|}{ Kepatuhan } & \multirow{3}{*}{ p-value } \\
\hline & \multicolumn{2}{|c|}{ Patuh } & \multicolumn{2}{|c|}{ Tidak Patuh } & \multicolumn{2}{|c|}{ Total } & \\
\hline & $\mathbf{f}$ & $\%$ & $\mathbf{f}$ & $\%$ & $\mathbf{f}$ & $\%$ & \\
\hline Baik & 16 & 53,3 & 0 & 0 & 16 & 53,3 & \\
\hline Cukup & 4 & 13,3 & 8 & 26,7 & 12 & 40,0 & 0,000 \\
\hline Kurang & 0 & 0 & 2 & 6,7 & 2 & 6,7 & \\
\hline Jumlah & 20 & 66,6 & 10 & 33,4 & 30 & 100 & \\
\hline
\end{tabular}

Sumber: Data Primer, 2020

Pada tabel 3 menunjukkan bahwa seluruh ibu hamil trimester III yang memliki pengetahuan baik sebanyak 16 ibu hamil (53,3\%) patuh mengkonsumsi tablet Fe. Kemudian dari 12 ibu hamil (40,0\%) yang memiliki pengetahuan cukup, 4 ibu hamil $(13,3 \%)$ patuh mengkonsumsi tablet $\mathrm{Fe}$ dan 8 ibu hamil (26,7\%) tidak patuh mengkonsumsi tablet Fe. Selanjutnya semua ibu hamil yang memiliki pengetahuan kurang sebanyak 2 ibu hamil (6,7\%) tidak patuh mengkonsumsi tablet Fe.

Berdasarkan hasil uji statistic ChiSquare menunjukkan nilai $p$-value $=0,000$ ( $p$-value $<0,05)$ yang berarti bahwa ada hubungan pengetahuan terhadap kepatuhan mengkonsumsi tablet Fe pada ibu hamil trimester III Di Puskesmas Cilacap Selatan I Kabupaten Cilacap.

\section{PEMBAHASAN}

Hasil uji Chi-Square yang diperoleh dalam penelitian ini yaitu $p$-value $0,000(p$-value $<0,05)$ menunjukkan bahwa ada hubungan pengetahuan terhadap kepatuhan mengkonsumsi $\mathrm{Fe}$ pada ibu hamil trimester III. Sebagian besar ibu hamil trimester III yang patuh mengkonsumsi
Fe memiliki pengetahuan baik, hal ini sejalan dengan penelitian yang menyatakan bahwa sebagian besar ibu hamil (52\%) memiliki tingkat pengetahuan baik tentang anemia (Putri Rimba Wati \& Kurnia Dewi, 2017). Penelitian lain menyatakan bahwa ada hubungan pengetahuan ibu hamil kejadian anemia (Sulasmi, 2016).

Perilakumengkonsumsitabletzatbesi $(\mathrm{Fe})$ selama hamil merupakan salah satu faktor risiko yang dapat mempengaruhi terjadinya anemia (Verrayanti, 2017). Menurut (Notoatmodjo, 2007) perilaku kesehatan merupakan sesuatu respon dari individu terhadap stimulus yang berkaitan dengan masalah kesehatan, penggunaan pelayanan kesehatan, pola hidup serta lingkungan sekitar yang mempengaruhinya.

Salah satu faktor yang dapat mempengaruhi perilaku kesehatan adalah pengetahuan (Notoatmodjo, 2007). Hal tersebut dapat dilihat dari ibu hamil trimester III yang memiliki pengetahuan baik, patuh mengkonsumsi tablet Fe. Hal tersebut didukung dengan penelitian yang menunjukkan bahwa pengetahuan merupakan salah satu faktor yang mempengaruhi konsumsi tablet zat besi (Fe) pada 
ibu hamil (Shofiana et al., 2018). Pengetahuan yang baik dapat mendorong kesadaran ibu hamil untuk mengkonsumsi tablet zat besi $(\mathrm{Fe})$ secara teratur selama kehamilan.

Pengetahuan merupakan proses yang dialami seseorang untuk mengetahui suatu hal melalui penginderaan terhadap suatu obyek tertentu, baik diperoleh secara formal maupun informal. Pengetahuan diperoleh secara informal misalnya dari media massa, pengalaman orang lain, keluarga atau pemberian informasi yang disampaikan oleh tenaga kesehatan. Pemberian informasi dalam bentuk penyuluhan oleh tenaga kesehatan menjadi faktor lain yang dapat mempengaruhi pengetahuan. Tenaga kesehatan tidak hanya memberikan informasi tentang tablet zat besi $(\mathrm{Fe})$, tetapi dapat pula memberikan dukungan untuk mengkonsumsi tablet besi $(\mathrm{Fe})$. Sehingga dengan informasi dan dukungan dari tenaga kesehatan dapat memudahkan tercapainya pemenuhan zat besi $(\mathrm{Fe})$ selama kehamilan.

\section{SIMPULAN DAN SARAN}

Berdasarkan hasil penelitian ini menunjukkan bahwa ada hubungan pengetahuan terhadap kepatuhan mengkonsumsi tablet $\mathrm{Fe}$ pada ibu hamil trimester III di Puskesmas Cilacap Selatan I. Oleh karena itu, perlu adanya upaya yang berkesinambungan untuk meningkatkan pengetahuan ibu hamil tentang anemia dengan melalui penyuluhan kesehatan atau metode lainnya, serta monitoring untuk kepatuhan dalam mengkonsumsi tablet Fe selama kehamilan.

\section{DAFTAR PUSTAKA}

Ayu Wulandari, I. (2018). Hubungan Tingkat Pengetahuan dengan Kejadian Anemia Pada Ibu Hamil di Puskesmas Jongaya Makassar Tahun 2018. Jurnal Kesehatan Delima Pelamonia, 2(2), 155-158. https://doi.org/10.37337/jkdp.v2i2.83

Kehutanan, P. M., Teknis, P., Hutan, R., Lahan,
D. A. N., Rahmat, D., Yang, T., Esa, M., \& Kehutanan, M. (2008). Peraturan menteri kesehatan republik indonesia nomor 88 tahun 2014 tentang standar tablet tambah darah bagi wanita usia subur dan ibu hamil dengan rahmat tuhan yang maha esa menteri kesehatan republik indonesia, Menimb. 96, 1-26.

Kemenkes RI. (2014). Profil Kesehatan Indonesia. Kementrian Kesehatan Indonesia. In Pusdatin.Kemenkes. Go.Id.

Mandagi, I. V. (2019). Hubungan tingkat pengetahuan anemia dengan kejadian anemia pada ibu hamil. 2(April), 31-39. https://doi.org/10.31227/osf.io/pd53t

Manuaba, I. B. G. (2010). Ilmu Kebidanan, Penyakit Kandungan dan Keluarga Berencana Untuk Pendidikan Bidan. EGC.

Mardhiah, A., \& Marlina, M. (2019). FaktorFaktor Yang Mempengaruhi Kepatuhan Mengkonsumsi Tablet Fe Pada Ibu Hamil. Window of Health: Jurnal Kesehatan, 2(3), 266-276. https://doi.org/10.33368/ woh.v0i0.182

Notoatmodjo, S. (2007). Promosi Kesehatan Dan Ilmu Perilaku. Rineka Cipta.

Parulian, I., Roosleyn, T., Tinggi, S., Kesehatan, I., \& Widya, J. I. (2016). Strategi dalam penanggulangan pencegahan anemia pada kehamilan. Jurnal Ilmiah Widya, 3(3), 1-9.

Putri Rimba Wati, M., \& Kurnia Dewi, R. (2017). Gambaran Pengetahuan Ibu Hamil Tentang Anemia Pada Kehamilan Di Puskesmas Grobogan Kabupaten Grobogan. Jurnal Kesehatan Ibu Dan Anak Akademi Kebidanan An-Nur, 11.

Riskesdas, K. (2018). Hasil Utama Riset Kesehata Dasar (RISKESDAS). Journal of Physics A: Mathematical and Theoretical, 44(8), 1-200. https://doi.org/10.1088/1751- 
$8113 / 44 / 8 / 085201$

Setiawati, S., Rilyani, Wandinii, R., Wardiah, A., \& Aryanti, L. (2014). Faktor-Faktor Yang Mempengaruhi Kejadian Anemia Pada Ibu Hamil Di Wilayah Kerja Puskesmas Sekampung Kabupaten Lampung Timur Tahun 2013. Jurnal Kesehatan Holistik, $8(2), 53-58$.

Shofiana, F. I., Widari, D., \& Sumarmi, S. (2018). Pengaruh Usia, Pendidikan, dan Pengetahuan Terhadap Konsumsi Tablet Tambah Darah pada Ibu Hamil di Puskesmas Maron, Kabupaten Probolinggo. Amerta Nutrition, 2(4), 356. https://doi.org/10.20473/amnt. v2i4.2018.356-363

Studi, P., Dokter, P., Kedokteran, F., Ilmu, D., Uin, K., \& Makassar, A. (2016). Hubungan kepatuhan konsumsi tablet fe terhadap kejadian anemia pada ibu hamil di kecamatan patallassang kabupaten gowa tahun 2016 Darmawansyih.
Darmawansyih Alami Journal, 1(1), 5159.

Sulasmi, S. (2016). Hubungan antara pengetahuan dan kepatuhan ibu hamil dalam mengkonsumsi tablet fe dengan kejadian anemia ibu hamil di puskesmas weru.

Sulistiyanti, A. (2015). Hubungan Tingkat Pengetahuan Ibu Hamil Tentang Anemia Dengan Kepatuhan Konsumsi Tablet Fe Di Wilayah Kerja Puskesmas Masaran I Sragen. Jurnal Kebidanan Dan Ilmu Kesehatan, 2(2), 8-22.

UNICEF, B. dan. (2017). Laporan Baseline SDG tentang Anak-Anak Di Indonesia, Bappenas dan UNICEF.

Verrayanti, R. M. D. (2017). Hubungan Tingkat Pengetahuan Dan Perilaku Konsumsi Tablet Tambah Darah Dengan Kejadian Anemia Pada Ibu Hamil Trimester Iii Di Puskesmas Mantrijeron Kota Yogyakarta Tahun 2017. 1689-1699. 